\title{
Cefcanel daloxate versus penicillin in acute streptococcal pharyngotonsillitis
}

\author{
A Grunfeld mD, P Sinclair, LE Nicolle mD AND the CANAdian TONSILlitis Study Group
}

\begin{abstract}
A Grunfeld, P Sinclair, LE Nicolle and the Canadian Tonsillitis Study Group. Cefcanel daloxate versus penicillin in acute streptococcal pharyngotonsillitis. Can J Infect Dis 1994;5(3):119-124.
\end{abstract}

OBJECrIvE: To determine the efficacy, safety and tolerance of cefcanel daloxate and phenoxymethylpenicillin $(\mathrm{PcV})$ in the treatment of acute pharyngotonsillitis caused by beta-hemolytic streptococci group A (BHSGA). Patients and Methods: Randomized, double-blind, multicentre study with subjects randomized 1:1:1:1 to four parallel treatment groups: cefcanel daloxate $150 \mathrm{mg}$ bid, $300 \mathrm{mg}$ bid, $600 \mathrm{mg}$ daily and PcV $300 \mathrm{mg}$ tid. Patients were treated for 10 days with clinical, bacteriological and safety evaluation at inclusion, during therapy (day 5), early after completion of therapy (day 14) and two weeks later (day 28).

REsults: Of 340 subjects enrolled, 324 were valid for safety analysis and 249 for efficacy analysis. At the short term visit, clinical cure rates for cefcanel daloxate $300 \mathrm{mg}$ bid and PcV groups were similar at approximately $70 \%$. The cure rates for cefcanel daloxate $150 \mathrm{mg}$ bid and $600 \mathrm{mg}$ daily were significantly worse at 57.4 and $54.4 \%$. Approximately $80 \%$ of all pretherapy throat swabs grew BHSGA. All BHSGA were susceptible or intermediately susceptible to $\mathrm{PcV}$ and cefcanel. The bacterial elimination rate for cefcanel daloxate was $82.8 \%$ and for $\mathrm{PcV}$ it was $89.8 \%$. The elimination rate was significantly lower in the cefcanel daloxate $150 \mathrm{mg}$ bid and $600 \mathrm{mg}$ daily groups. The clinical cure rates and the bacteriological elimination rates increased by about 10\% for cefcanel daloxate $300 \mathrm{mg}$ bid and the $\mathrm{PcV}$ groups at the last valid visit and remained significantly better than the other two cefcanel daloxate doses. Adverse events were not significantly different among the four treatment groups.

Conclusions: Cefcanel daloxate $300 \mathrm{mg}$ bid was as effective and as well tolerated as PcV $300 \mathrm{mg}$ tid in the treatment of acute pharyngotonsillitis. A lower dose or once-daily dose regimen of cefcanel daloxate was not as effective clinically or bacteriologically. (Pour résumé, voir page 120)

Key Words: Cefcanel daloxate, Group A streptococcus, Penicillin V, Tonsillitis

Vancouver General Hospital, Vancouver, British Columbia; Departments of Internal Medicine and Medical Microbiology. University of Manitoba; and Health Sciences Centre, Winnipeg, Manitoba

Canadian Tonsillitis Study Group: listed by order of study centre number with corresponding number of patients enrolled: 01-Dr D Shires, Dalhousie Family Medical Centre, Halifax (12); 02-Dr M Slutchuk and Dr LE Nicolle, University of Manitoba. Winnipeg (17); 03-Dr R Shearer, London (21); 04-Dr A Grunfeld, Vancouver General Hospital, Vancouver (22); 05-Dr J Dreyer, Victoria Hospital, London (1 1); 06-Dr J Fodor and Dr A Chockalingam, Memorial University of Newfoundland, St John's Regional Hospital, Saint John's (5); 09-Dr S Shafran, University of Alberta Hospital, Edmonton (7); 10-Dr M Tarrant and Dr K Buchan, Health Sciences Centre, Calgary (1): 11-Dr M Shulman, Royal Victoria Hospital, Montreal, (43); 12-Dr R Ladouceur, Clinique de médicine familiale, Verdun (25); 14-Dr L Latulippe, Centre hospitalier de l'Université Laval, Ste-Foy (5); 15-Dr T MacFarlene, University of Western Ontario, London (12); 16-Dr R Guibert, Unité de médicine familiale de la Cité de la Santé de Laval, Laval (14); 19-Dr J Dubois and Dr C St-Pierre, Centre hospitalier Hôtel-Dieu de Sherbrooke, Sherbrooke (48)

Correspondence and reprints: Dr LE Nicolle, MS 675D, Health Sciences Centre, 820 Sherbrook Street. Winnipeg. Manitoba R3A 1R9. Telephone (204) 787-4655, Fax (204) 787-4699

Received for publication September 14, 1992. Accepted December 6, 1993 


\section{Cefcanel daloxate versus pénicilline dans la pharyngoamygdalite streptococcique aiguë}

OBJectif : Déterminer l'efficacité, l'innocuité et la tolérabilité du cefcanel daloxate et de la phênoxyméthylpénicilline $(\mathrm{PCV})$ dans le traitement de la pharyngoamygdalite aiguë, causée par des streptocoques bêta-êvolutifs du groupe A.

Matériel et Méthode : Étude multicentrique randomisée à double insu auprès de sujets randomisés à 1:1:1:1 entre quatre groupes thérapeutiques parallèles : cefcanel daloxate $150 \mathrm{mg}$ bid, $300 \mathrm{mg}$ bid, $600 \mathrm{mg}$ par jour et PcV $300 \mathrm{mg}$ tid. Les patients ont été traités durant 10 jours avec une évaluation clinique bactériologique et une évaluation d'innocuité à l'amorce et durant le traitement (jour 5), tôt après la fin du traitement (jour 14) et deux semaines plus tard (jour 28).

Résultats : Des 340 sujets inscrits, 324 se conformaient à l'analyse d'innocuité et 249 à l'analyse d'efficacité. À la visite court-terme, les taux de guérison clinique pour cefcanel daloxate $300 \mathrm{mg}$ bid et PcV étaient semblables à environ $70 \%$. Les taux de guérison pour cefcanel daloxate $150 \mathrm{mg}$ bid et $600 \mathrm{mg}$ par jour étaient nettement moindres à $57,4 \%$ et $54,4 \%$. Environ $80 \%$ de tous les prélèvements de gorge pré-traitement ont permis la croissance de streptocoques bêta-évolutifs du groupe A. Ces derniers étaient sensibles ou modérément sensibles à la $\mathrm{PcV}$ et au cefcanel. Le taux d'élimination bactérienne pour le cefcanel daloxate a été de $82,8 \%$ et pour le PcV de $89,8 \%$. Le taux d'élimination était nettement plus bas dans les groupes cefcanel daloxate $150 \mathrm{mg}$ bid et $600 \mathrm{mg}$ par jour. Les taux de guérison clinique et d'élimination bactériologique ont augmenté d'environ $10 \%$ pour le groupe cefcanel daloxate $300 \mathrm{mg}$ bid et PcV lors de la dernière visite valide et sont demeurés nettement meilleurs qu'avec les deux autres doses de cefcanel daloxate. Les réactions indésirables ne se sont pas révélées nettement différentes entre les quatre groupes thérapeutiques.

Conclusion : Le cefcanel daloxate $300 \mathrm{mg}$ bid a été aussi efficace et aussi bien toléré que la PcV $300 \mathrm{mg}$ tid dans le traitement de la pharyngoamygdalite aiguë, une dose plus faible ou un schéma thérapeutique uniquotidien de cefcanel daloxate ne s'est pas révélé aussi efficace sur le plan clinique et bactériologique.

$\mathrm{S}$ TREPTOCOCCAL PHARYNGOTONSILLITIS SHOULD BE TREATED with antibiotics. Phenoxymethylpenicillin (PcV) has been the agent of choice worldwide since its introduction. This antimicrobial agent is relatively inexpensive and has few side effects. Several studies, however, have reported high clinical and bacteriological failure rates after treatment with $\mathrm{PcV}$, with 19 to $30 \%$ bacteriological persistence in the pharynx after PcV therapy (1-4). Penicillin-resistant group A streptococcus has not been identified to explain this failure rate. The poor outcomes may be due to poor compliance, inactivation of penicillin by penicillinase-producing bacterial species in the pharynx, improper dose or inadequate antibacterial activity at the infection site (4). The bacteriological failure with other antimicrobials, particularly oral cephalosporins, ranges from 2 to $14 \%$, rates lower than those seen with PcV (2-9). For some cephalosporins, once- or twice-daily dosing regimens are as effective as or superior to $\mathrm{PcV}$ in the treatment of streptococcal pharyngotonsillitis (4,7-9).

Cefcanel daloxate is a cephalosporin prodrug for oral use (10). It demonstrates improved in vitro activity against Gram-positive bacteria compared with cephalexin, cefadroxil and cefaclor, and retains activity against Gram-negative bacteria. Cefcanel daloxate is similar to cefaclor with respect to beta-lactamase stability, although each drug demonstrates slightly different stability depending on the type of beta-lactamase tested. The prodrug becomes active only after hydrolysis in the intestinal lumen and mucosa to cefcanel. carbon dioxide and diacetyl. The active antibacterial component, cefcanel, is released into the circulation (10).
The present study was conducted to investigate the efficacy, safety and tolerance of three dosage regimens of cefcanel daloxate (150 mg bid, $300 \mathrm{mg}$ bid and $600 \mathrm{mg}$ daily) compared with $\mathrm{PcV}$ (300 mg tid) in adult and adolescent patients with acute beta-hemolytic streptococci group A (BHSGA) pharyngotonsillitis. It was hypothesized that the prodrug characteristic and betalactamase stability of cefcanel daloxate would produce better tolerance and lower bacteriological failure rates.

\section{PATIENTS AND METHODS}

Study design: This was a Canadian multicentre study. The study was double-blind, computer randomized and used parallel treatment groups. Study investigators were general practitioners, emergency physicians and infectious disease specialists. The study was approved by each of the applicable institutional or regional ethics committees.

Patient population: A total of 340 patients was enrolled in the study at 16 Canadian centres. Out-patients of either sex between 12 and 80 years of age were eligible. In addition, patients had one or more of the following signs of acute pharyngotonsillitis: fever, tonsillar erythema, exudate or hypertrophy. A positive rapid screen test indicating BHSGA in the tonsillar area (Phadirect, Pharmacia or Strep A Test Pack, Abbott Laboratories Ltd) was required for inclusion, with subsequent confirmation through bacteriological culture. Written informed consent was obtained.

Patients were excluded if they had concomitant infections other than pharyngotonsillitis, with known or suspected allergies to penicillin or cephalosporins, or if they had received antimicrobial treatment within seven 
days of entry. Patients with severe underlying disease, immunological deficiencies, impaired liver or renal function, and/or pregnant or lactating females were also not eligible. Subjects were enrolled only once.

Treatment regimens: Treatment with cefcanel daloxate 150 or $300 \mathrm{mg}$ bid, $600 \mathrm{mg}$ once per day, or PcV $300 \mathrm{mg}$ tid was allocated randomly at a ratio of $1: 1: 1: 1$. No dosage adjustment was allowed. Drugs were dispensed using a double-dummy technique. Duration of treatment was 10 days in each group. Patients were instructed to take the medication in a fasting state, $1 \mathrm{~h}$ before or $2 \mathrm{~h}$ after meals. Compliance was checked by asking patients to return drug packaging at the third visit. Patients also completed a diary card for the first 10 days of the study, indicating daily symptoms and temperature. The diary card also contained instructions reminding the patient to take doses in the morning, midday and evening. Treatment with other antimicrobial drugs was prohibited during the study period.

Microbiological methods: A rayon-tipped swab was used to collect a sample from the tonsillar, uvula and soft palate areas at inclusion and follow-up visits. Swabs were transported to local microbiological laboratories for culture on sheep blood agar plates. Plates were incubated at $37^{\circ} \mathrm{C}$ for 18 to $24 \mathrm{~h}$ and subsequently examined for growth of beta-hemolytic streptococci. Colonies of BHSGA were quantified and isolated, and Lancefield grouping performed. In vitro susceptibility of all isolates to cefcanel daloxate and $\mathrm{PcV}$ was determined using the Kirby Bauer disc diffusion method. Susceptibility was reported as sensitive, intermediate or resistant, with corresponding zone diameters measured in millimetres. All laboratories assessed beta-lactamase activity using the nitrocefin test with results reported as 'yes' or 'no'. Beta-hemolytic streptococci were suspended in Todd-Hewitt broth and stored at $-70^{\circ} \mathrm{C}$.

At study termination, strains were thawed, checked for viability and sent to the National Centre for Streptococcus at the Provincial Laboratory of Public Health for Northern Alberta (University of Alberta, Edmonton, $\mathrm{Al}$ berta T6G 2J2). Cultures were plated, grown and Lancefield grouped to confirm the assigned group. M typing, T agglutination and serum opacity factor were performed for all BHSGA. Strains that had a positive serum opacity reaction and were ' $M$ ' nontypable were further analyzed with respect to antiopacity factor typing. In addition, all strains were tested for susceptibility to cefcanel and benzylpenicillin using the agar dilution technique to obtain the $90 \%$ minimum inhibitory concentration (MIC90).

Assessment: Patients were required to visit the clinic four times: at entry, during therapy (day 5), after therapy (day 14) and at long term follow-up (day 28). Clinical, bacteriological and safety evaluations were performed at each clinic visit. Age, sex, medical history, concomitant disease and baseline medical events were recorded at the first visit, and the patient was subjected to a physical examination. Oral temperature was recorded. Pharyngeal status, including tonsillar erythema, exudate and hypertrophy, was assessed as 'yes' or 'no'. The patient's subjective assessment of feeling of illness, sore throat and fever was also recorded as 'yes' or 'no'. Signs and symptoms were similarly recorded at the second, third and fourth visits.

Adverse events: All adverse events spontaneously reported by the patient or observed by the investigator were registered. At follow-up visits, a nonspecific question, such as "apart from your disease, have you experienced any other symptoms, illness or injury since we last met?" was asked. Adverse events were recorded with respect to description/diagnosis, date of onset, duration, severity, causal relationship to study drug, final outcome and the source of information.

Venous blood samples and midstream urine samples were collected at the initial, second and third visits. Analysis was performed at each centre, and included: hemoglobin, leukocytes, thrombocytes, activated partial thromboplastin time, erythrocyte sedimentation rate, Coomb's test, sodium, potassium, alanine aminotransferase, aspartate aminotransferase, alkaline phosphatase, gamma glutaryl transpeptidase, bilirubin, creatinine and routine urinalysis.

Outcome assessment: Clinical outcome was classified as cure, improvement, failure and recurrence. Cure was defined as the disappearance of all signs and/or symptoms, and recurrence was the reappearance of signs and/or symptoms after an interval free from symptoms. Patients withdrawn from the study during treatment due to lack of effect were classified as an 'early treatment failure'.

Bacteriological outcome was defined as elimination, persistence, relapse, reinfection or unassessable. Elimination was defined as the eradication of BHSGA of the original type, while persistence was the repeat isolation of the same type. Reinfection was defined as recolonization with a type different from the original, and relapse was recolonization with the same type as the original with intervening negative cultures. Cases with culture not available were considered unassessable. Patients who were asymptomatic on third or fourth visit but continued to harbour BHSGA of the same type isolated at enrolment were considered to be 'carriers'.

Statistical analysis: The primary comparison was for the short term (visit 3) bacteriological and clinical outcomes among the treatment groups using pairwise Wilcoxon two-sample tests. To be valid for these analyses, subjects were required to have their third visit before day 20 , and to have taken at least five days of study medication, unless they were an early treatment failure, ie, given other antimicrobial treatment before posttreatment follow-up due to lack of response. The above comparisons were also applied to the last valid visit results up to day 45 . Interim analyses were performed by an independent group when patient enrolment 
TABLE 1

Clinical response at short term (early) and last valid visit (late) for patients valid for efficacy

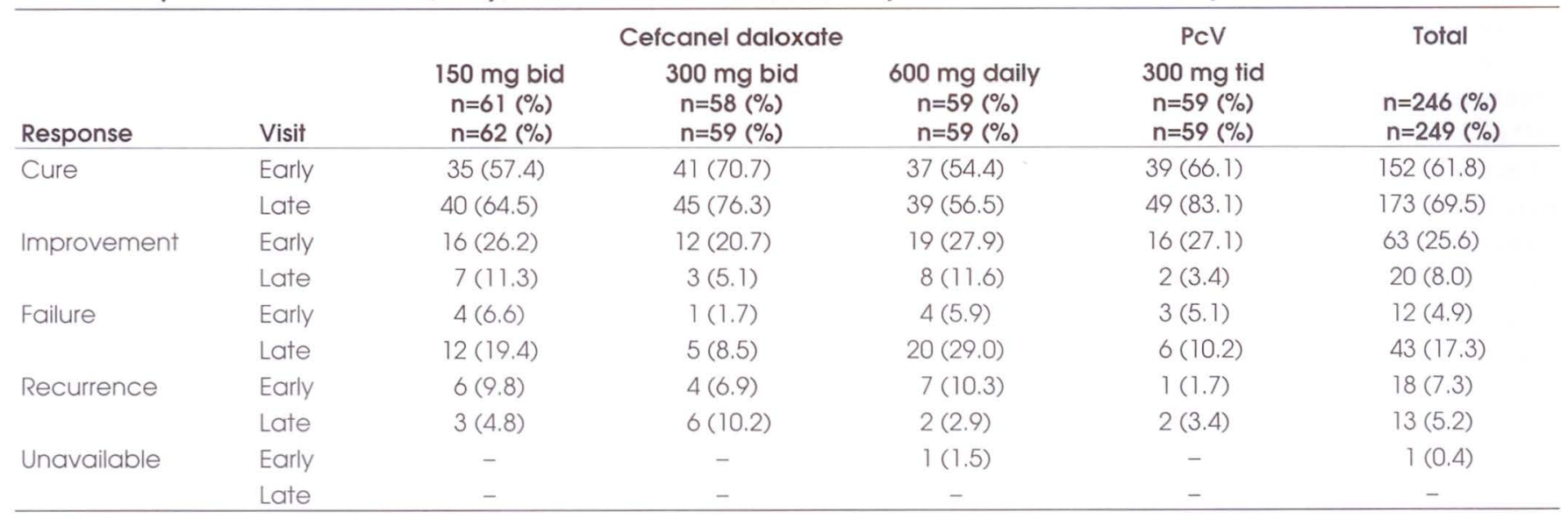

PCV Phenoxymethylpenicillin

reached 96 and 200. The interim results were not transmitted to the project study group so there was no effect on study outcome.

\section{RESULTS}

Patients: From July 1988 to February 1991, 340 patients were enrolled in the study. At completion, 324 patients were valid for safety evaluation and 249 for efficacy analysis. Sixteen patients not included in the safety evaluation were lost to follow-up. In addition, 75 patients were not valid for efficacy analysis for the following reasons: age (two patients aged 10 and 11 years), adverse effects (two), clinical deterioration (one), patient refusal (four), no BHSGA on the first visit (55) and no valid follow-up visit (11). The proportion of patients evaluable for efficacy was consistent in the four treatment groups, ranging from 59 in the cefcanel daloxate $300 \mathrm{mg}$ bid group to 69 in the cefcanel daloxate $600 \mathrm{mg}$ daily group. For all randomized patients, and for patients retained for efficacy analysis, the four treatment groups were similar with respect to age, sex, weight, background medical history, concomitant diseases, concomitant medications and the presence of signs and symptoms at the initial visit.

Clinical efficacy: Thirty patients had visit 3 outside the initially established window of day 12 to 16 . To include as many of these patients as possible in the efficacy analysis, the window was widened to day 10 to 20 , provided the patients discontinued study drug at least one day before the follow-up visit. Analysis was not significantly different when these patients were included with the original short term efficacy group. Three patients were excluded from the short term analysis because they did not have a valid third visit.

No significant differences were found in the clinical outcome at the short term visit $(\mathrm{P}=0.1764$, KruskalWallis test) (Table 1). The cure rate was approximately $70 \%$ in both the $300 \mathrm{mg}$ bid cefcanel daloxate and the $\mathrm{PcV}$ groups. The cure rate was lower in the cefcanel daloxate $150 \mathrm{mg}$ bid group (57.4\%), approximately 10 to $15 \%$ below those of the cefcanel daloxate $300 \mathrm{mg}$ and $\mathrm{PcV}$ groups. Recurrences tended to be more frequent in all cefcanel daloxate groups compared with the PcV group.

At the last valid visit the cure rate increased in the $300 \mathrm{mg}$ cefcanel daloxate and the PcV groups by approximately $10 \%$ to a rate of $80 \%$ (Table 1). Using pair-wise Wilcoxon one-sample tests, significant differences were found between $150 \mathrm{mg}$ cefcanel daloxate and $\mathrm{PcV}(\mathrm{P}=0.027)$, between $300 \mathrm{mg}$ and $600 \mathrm{mg}$ cefcanel daloxate $(\mathrm{P}=0.011)$ and between $600 \mathrm{mg}$ cefcanel daloxate and PcV ( $\mathrm{P}=0.001)$.

Bacteriological efficacy: Of the 277 patients with BHSGA on the first visit, 246 had cultures obtained at the first post-therapy visit and were valid for short term efficacy analysis. At the short term visit the elimination, relapse and persistence rates were comparable in the cefcanel daloxate $300 \mathrm{mg}$ and the $\mathrm{PcV}$ groups $(\mathrm{P}=0.21)$ (Table 2). The difference between the worst group $(600$ $\mathrm{mg}$ cefcanel daloxate) and the $300 \mathrm{mg}$ cefcanel daloxate and PcV groups, respectively, was statistically significant ( $\mathrm{P}=0.0001$ for both). High dose once daily (600 mg) cefcanel daloxate had a significantly poorer elimination rate than $150 \mathrm{mg}$ bid ( $\mathrm{P}=0.023)$. Approximately $20 \%$ of patients in both of these groups had relapses (Table 2). The incidence of reinfection was low in all treatment groups. Persistence occurred significantly more frequently for the $150 \mathrm{mg}$ bid cefcanel daloxate group or the $600 \mathrm{mg}$ cefcanel daloxate group compared with either $300 \mathrm{mg}$ bid cefcanel daloxate or $\mathrm{PcV}(\mathrm{P}<0.01$, all comparisons).

At the last valid visit (Table 2) bacteriological outcome was similar for cefcanel daloxate $300 \mathrm{mg}$ bid and $\mathrm{PcV}$ groups. There were statistically significant differences in elimination rates in the low and high dose cefcanel groups compared with the $300 \mathrm{mg}$ cefcanel daloxate and the $\mathrm{PcV}$ groups $(\mathrm{P}<0.001)$. No significant difference was found between the low and high dose cefcanel daloxate groups $(\mathrm{P}=0.057)$. Relapse rates were 
TABLE 2

Bacteriological outcomes at short term (early) and last valid visit (late) for patients valid for efficacy analysis

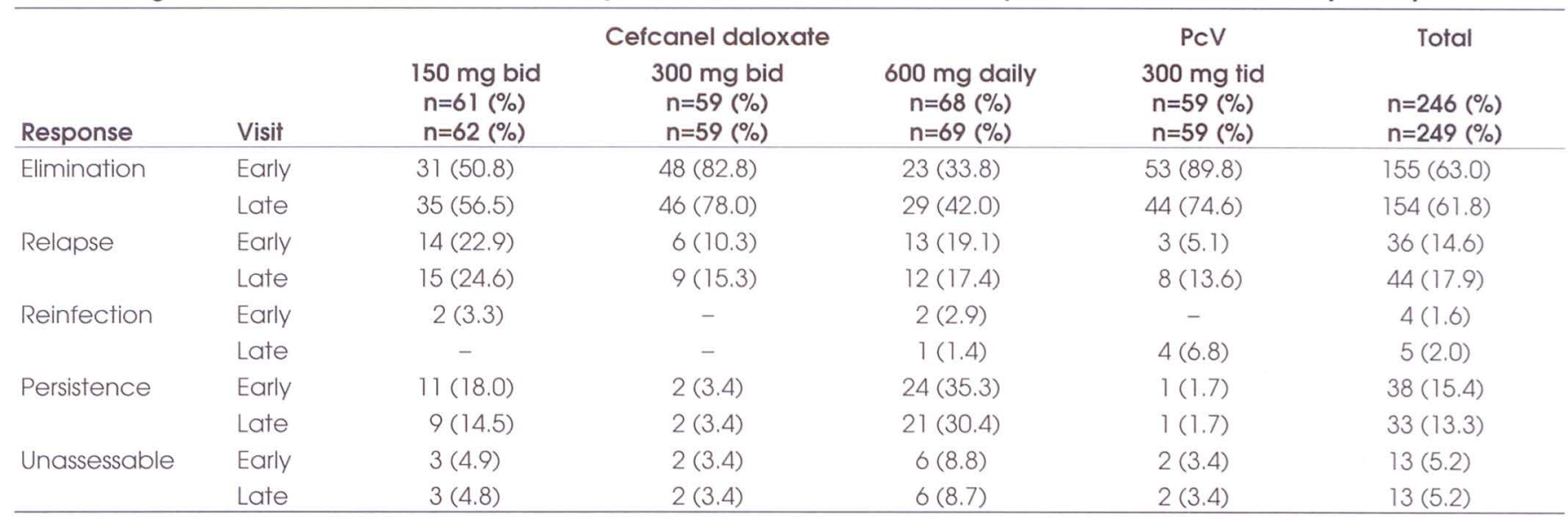

PCV Phenoxymethylpenicillin

similar in the four treatment groups. Persistence was lower for the low and high dose cefcanel daloxate groups, but remained elevated for both relative to cefcanel daloxate $300 \mathrm{mg}$ bid and PcV groups.

The bacteriological type and frequency of all strains isolated at the first visit for all cases with relapse is shown in Table 3. Eighteen distinct types were isolated, with M1T1, M2T2, T28 and M12T12 types isolated from over 50\% of all relapses. Eight patients had reinfections at the third or fourth visit with a strain not of the same type as that at inclusion.

Thirty-one patients at the short term visit and 22 patients at the last valid visit were clinically cured but had persistent growth of BHSGA, meeting the criteria for 'carriers'. The high dose cefcanel daloxate group had a significantly higher rate of bacteriological persistence (Table 2). The low dose cefcanel daloxate group also had more bacteriological persistence than the cefcanel daloxate $300 \mathrm{mg}$ bid and the PcV groups, but not as elevated as the high dose cefcanel daloxate group.

Safety: A total of 324 patients was evaluable for safety. The number of patients reporting adverse events was not significantly different in the four treatment groups, ranging from 39 with cefcanel daloxate 150 bid to 51 in the cefcanel daloxate $600 \mathrm{mg}$ daily group. No significant differences were detected among treatment groups with respect to single symptoms. When symptoms were grouped using World Health Organization codes into system organ classes, for 'body as a whole - general disorders', cefcanel daloxate $150 \mathrm{mg}$ bid was significantly better than cefcanel $300 \mathrm{mg}$ bid (P=0.014) and $600 \mathrm{mg}$ once daily $(\mathrm{P}=0.02)$. No significant differences were detected between all cefcanel daloxate groups and the PcV group. Most adverse events were mild and the distribution of severity was equal in the four treatment groups.

Four patients discontinued study medication due to adverse events, all with nausea and vomiting. Two of these were in the cefcanel daloxate $150 \mathrm{mg}$ bid group
TABLE 3

Frequency of beta-hemolytic streptococcus group A types for all relapses

\begin{tabular}{rcccc}
\hline \multicolumn{5}{c}{ Typing mechanism } \\
M Type & T Type & $\begin{array}{c}\text { Opacity } \\
\text { factor }\end{array}$ & $\begin{array}{c}\text { Anitopacity } \\
\text { factor type }\end{array}$ & $\begin{array}{c}\text { Number of } \\
\text { strains }\end{array}$ \\
\hline 1 & 1 & - & NA & 18 \\
2 & 2 & + & 2 & 16 \\
NA & 28 & + & 28 & 12 \\
12 & 12 & - & NA & 10 \\
78 & 11 & + & 78 & 7 \\
6 & 6 & - & NA & 7 \\
4 & 4 & + & NA & 6 \\
NT & 12 & + & 22 & 6 \\
3 & 3 & - & NA & 4 \\
4 & 4 & + & 4 & 1 \\
5 & $5,27,44$ & - & NA & 2 \\
2 & 2 & + & NA & 3 \\
9 & 9 & + & NA & 2 \\
NA & 28 & + & NT & 2 \\
NT & 3,13, B3264 & + & NT & 2 \\
NT & 3, B3264 & + & NT & 2 \\
NA & 28 & + & NT & 2 \\
22 & 12 & + & 22 & 1 \\
\hline Present: - Absent: NA Notapplicable: NT Nontypable &
\end{tabular}

+ Present; - Absent; NA Not applicable; NT Nontypable

and two were in the cefcanel daloxate $600 \mathrm{mg}$ once daily group. Two patients were hospitalized, one with a peritonsillar abscess and another with persisting fever and worsening infection. Both patients recovered with intravenous antibiotics.

\section{DISCUSSION}

$\mathrm{PcV}$ is considered to be the agent of choice for the treatment of streptococcal pharyngotonsillitis, despite reported failure rates as high as 30\% (1-4). Reported bacteriological failure for oral cephalosporins ranges from 2 to 14\%, a third lower than that reported with PcV (2-9). High bacteriological failure rates have been at- 
tributed to poor patient compliance, inactivation of penicillin by penicillinase-producing bacterial species in the pharynx, or improper dose or inadequate antibacterial activity at the infection site. Poor patient compliance is unlikely to be the sole reason for high failure rates with penicillin, because both oral and intramuscular administration give similar outcomes $(1,6)$. Inadequate concentration of antibiotics at the infection site has also been excluded for penicillin and cefadroxil (11). Penicillin tolerance also does not appear to contribute to the failure rates $(11,12)$. Several authors have, however, suggested an association between the presence of beta-lactamase-secreting organisms in the pharynx and the failure of penicillin therapy.

In the present study, three doses of cefcanel daloxate were chosen to bracket the doses of cephalosporins that had been used in other tonsillitis studies (4-9). The prodrug characteristics, pharmacokinetics and betalactamase stability of cefcanel daloxate were expected to produce better tolerance and less bacteriological failure. Clinical efficacy and bacteriological elimination rates were comparable in the cefcanel $300 \mathrm{mg}$ bid and $\mathrm{PcV}$ groups. Clinical and bacteriological outcomes for the other two cefcanel daloxate regimens, $150 \mathrm{mg}$ bid and $600 \mathrm{mg}$ daily, were significantly poorer. This is likely due to inadequate dose and frequency, respectively. Reported adverse events were similar in the four treatment groups, and were most commonly gastrointestinal. Serious adverse events and treatment discontinuations due to adverse events occurred rarely.

The study shares one weakness with other tonsillitis studies: it does not allow the separation of patients with viral upper respiratory tract infection and chronic streptococcal carrier state from patients with true BHSGA tonsillopharyngitis. Clinical assessment performed at day 5 of therapy may not identify the rapid clinical improvement noted at 24 to $48 \mathrm{~h}$ after initiation of appropriate antibiotic therapy. In addition, acute or

\section{REFERENCES}

1. Gastanaduy AS, Kaplan EL, Huwe BB, et al. Failure of penicillin to eradicate group A streptococci during an outbreak of pharyngitis. Lancet 1980;ii:498-501.

2. Breese BB, Denny FW, Dillon HC, Stillerman M, Nelson JD, McCarcken GH Jr. Consensus: difficult management problems in children with streptococcal pharyngitis. Pediatr Infect Dis 1985;6:10-3.

3. Stillerman M, Isenberg H, Moody M. Streptococcal pharyngitis therapy. Am J Dis Child 1972;123:457-61.

4. Milatovich D, Knauer J. Cefadroxil versus penicillin in the treatment of streptococcal tonsillopharyngitis. Eur J Clin Microbiol Infect Dis 1989;8:282-8.

5. Ginsburgh CM, McCracken GH, Crow SD, et al. A controlled comparative study of penicillin $\mathrm{V}$ and cefadroxil therapy of group A streptococcal tonsillopharyngitis. J Int Med Res 1980;8(Suppl 1):82-6,

6. Henness DM. A clinical experience with cefadroxil in upper respiratory tract infections. J Antimicrob Chemother 1982; 10(Suppl B): 125-35.

7. Gerber MA, Randolph MF, Chanatry J, et al. Once daily therapy for streptococcal pharyngitis with cefadroxil. J Pediatr 1986;109:531-7.

8. Pichichero ME, Disney FA, Aronovitz GH, et al. Randomized, convalescent streptococcal serology to confirm the diagnosis was not obtained. The prevalence of BHSGA carrier status in the general population is, however, approximately $10 \%$ (13) and, because of randomization, should not influence results within treatment groups.

There is a large number of antibiotics available that are effective for the treatment of streptococcal pharyngotonsillitis. Symptomatic response for the acute clinical illness and prevention of acute rheumatic fever is achieved with antibiotics that can be given twice daily, including penicillin V $(14,15)$. However, approximately every fifth patient treated with penicillin for acute BHSGA pharyngotonsillitis continues to harbour the bacteria after treatment. While it has been questioned what additional significant benefit would result from the eradication of the carrier state, few epidemiological data are available to determine whether these patients can be considered a source of infection or whether they are at an increased risk of developing post-streptococcal sequelae.

There is a trend for decreasing dose intervals in antimicrobial therapy, potentially reducing adverse effects as well as improving cost, compliance and convenience for the patient. This study demonstrates that, for cefcanel, there is a point at which therapy becomes less effective. The lowest dose regimen was clearly inadequate. Conversely, the once-daily regimen was not of sufficient dosing frequency for the half-life of the study medication. Cefcanel daloxate $300 \mathrm{mg}$ bid, however, was equivalent to PcV tid in outcomes. If an objective of treatment is to eradicate the carrier state, however, antibiotics with more favourable pharmacokinetics and therapeutic efficacy will need to be developed for treating this disease.

ACKNOWLEDGEMENTS: Supported by a grant from Astra Pharma Inc.

single blind evaluation of cefadroxil and phenoxymethylpenicillin in the treatment of streptococcal pharyngitis. Antimicrob Agents Chemother 1987:31:903-6.

9. Pichichero ME, Disney FA, Gerson H, et al. A multicentre, randomized, single-blind evaluation of cefuroxime axetil and phenoxymethylpenicillin in the treatment of streptococcal pharyngitis. Clin Pediatr 1987;26:453-8.

10. Kakeya N, Nishizawa S, Nishimura KI, et al. KY-109, a new bifunctional prodrug of a cephalosporin. Chemistry, physicochemical and biological properties. J Antibiot 1985;38:380-9.

11. Stromberg A. Studies on group A streptococcal pharyngotonsillitis. Diagnostic and therapeutic aspects. Doctoral Pediatr 1987;26:453-8.

12. Feldman S, Bisno AL, Lott L, et al. Efficacy of benzathine penicillin $\mathrm{G}$ in group A streptococcal pharyngitis: re-evaluation. J Pediatr 1987;110:783-7.

13. Bromberg A, Schwan A, Cars O. Throat carrier rates of beta-hemolytic streptococci among healthy adults and children. Scand J Infect Dis 1988;20:411-7.

14. Breese RB, Disney FA, Talpey WB. Penicillin in streptococcal infections. Am J Dis Child 1965;110:125-30.

15. Rosenstein BJ, Markowitz M, Goldstein E, et al. Factors involved in treatment failures following oral penicillin therapy of streptococcal pharyngitis. J Pediatr 1986;73:513-20. 


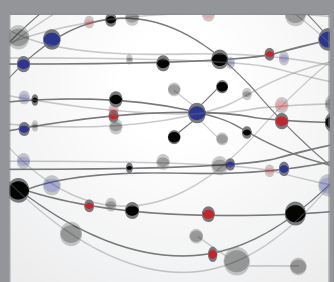

The Scientific World Journal
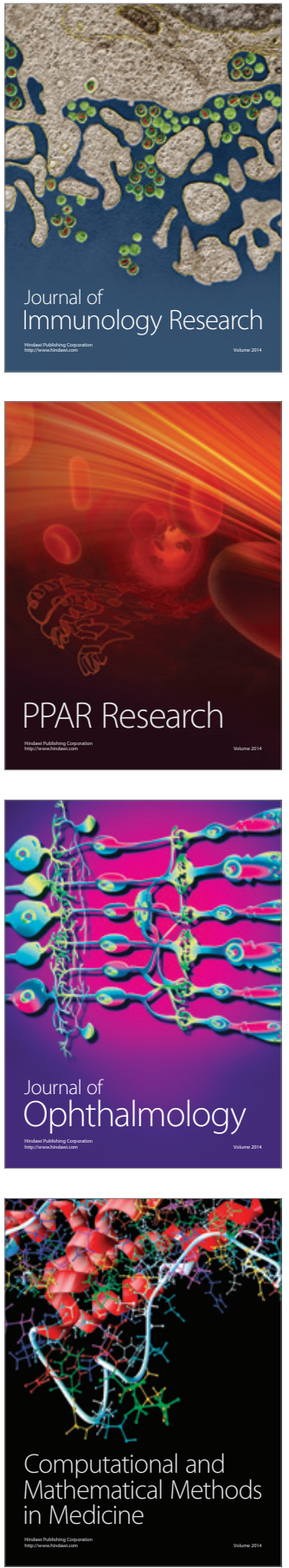

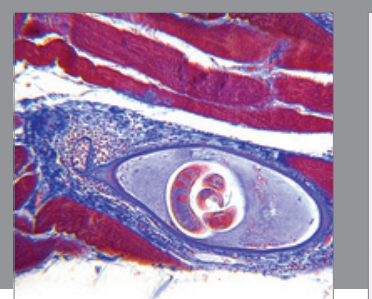

Gastroenterology Research and Practice

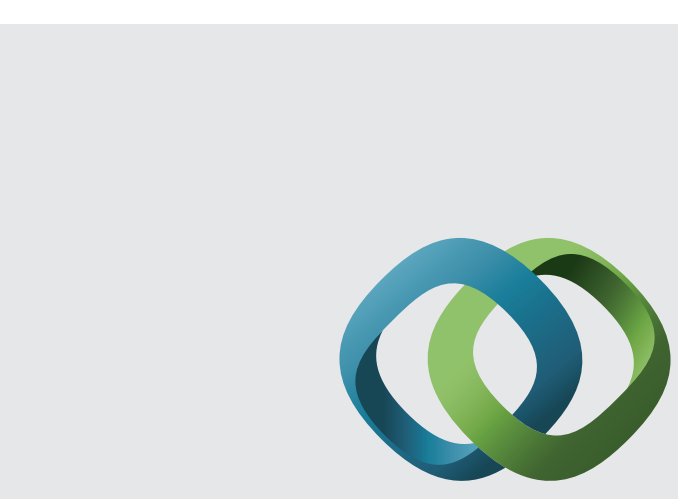

\section{Hindawi}

Submit your manuscripts at

http://www.hindawi.com
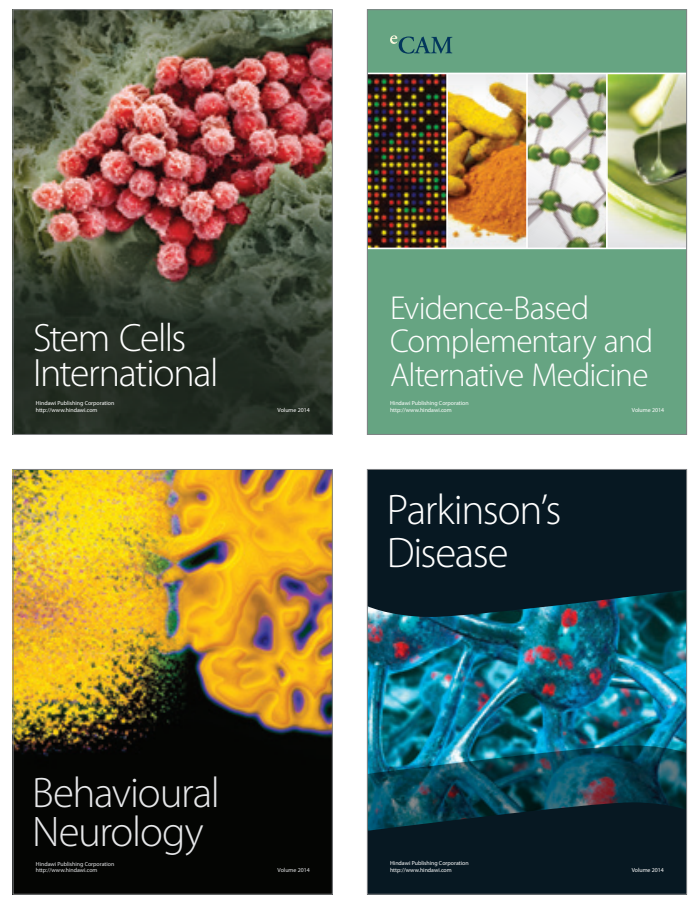
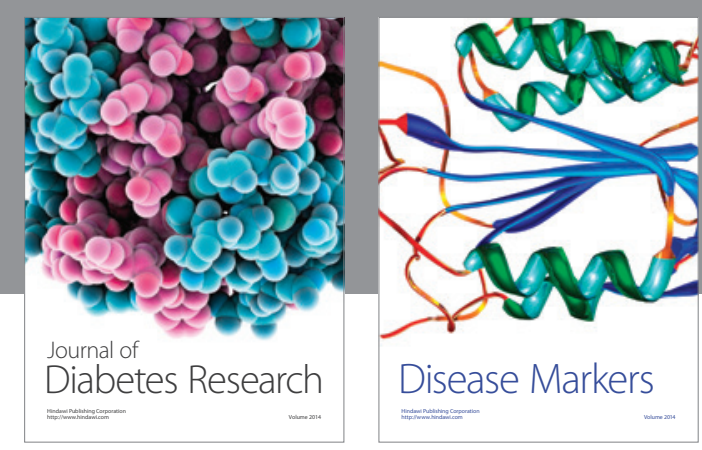

Disease Markers
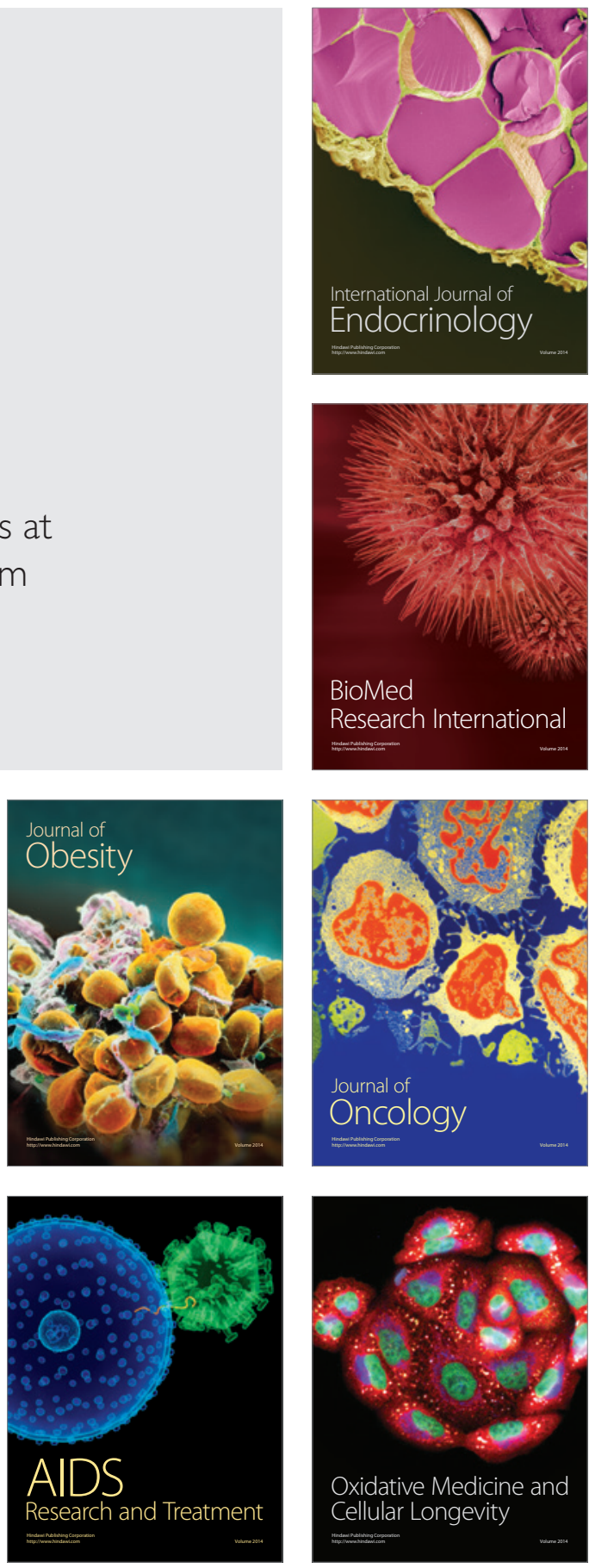